\title{
As veias abertas da América Latina: um ensaio sobre Araya
}

Natalia Christofoletti Barrenha

1 Doutoranda no Programa de Pós-Graduação em Multimeios (Unicamp), no qual desenvolve um projeto sobre a representação do espaço urbano no cinema argentino contemporâneo com apoio Capes. nataliacbarrenha@gmail. com. 


\section{Resumo}

O desejo de revelar as realidades conflitivas de seus países estimulou os cineastas latino-americanos a explorarem o potencial político do cinema e, especialmente, do documentário, a partir de 1950. Em um contexto de aceleradas mudanças, sob a égide do desenvolvimentismo, diversos diretores voltaram seus olhares a territórios marginalizados do continente. Questionaram também os reais benefícios que a modernização traria ao histórico de exploração vivido pela América Latina. Araya (Margot Benacerraf, 1959, Venezuela) aborda essa questão ao acompanhar 24 horas de uma comunidade que vive da pesca e da produção artesanal de sal na península de Araya. Pretendemos analisar como Margot Benacerraf aproximase desse universo e como se posiciona com relação às bruscas modificações que Araya está por viver. Estabelece, ainda, conexões com outros documentários da região que propunham uma abordagem semelhante.

\section{Palavras-chave}

Araya, Margot Benacerraf, documentário latino-americano.

\section{Abstract}

The desire to reveal the conflicting realities of their countries of origin encouraged Latin American filmmakers to explore the political potential of cinema and more specifically of the documentary in 1950. In a context of accelerated changes under the aegis of development, many filmmakers turned their eyes to marginalized areas of the continent. They have also questioned the real benefits that modernization could bring against the historical exploitation suffered by Latin America. Araya (Margot Benacerraf, 1959, Venezuela) addresses this issue by following 24 hours of a community living from fishing and handicraft production of salt in the peninsula of Araya. We intend to analyze how Margot Benacerraf approaches such universe and how she positions herself concerning the sudden changes that are about to happen in Araya, and to establish connections with other documentaries in the region that proposed a similar approach.

\section{Keywords}

Araya, Margot Benacerraf, Latin America documentary. 


\section{Itinerários do subdesenvolvimento e o cinema documentário}

Na América Latina, o cinema documentário adquiriu uma nova relevância na transição entre a era dos estúdios e o cinema independente. Sua renovação precedeu à do cinema de argumento, e a influenciou. Além disso, naquele momento, a década de 1950, os planos de modernização como vetores da mundialização do desenvolvimento dominavam o cenário. O filme documentário tornou-se arena para o debate político, cultural e social na região. Começaram a se manifestar olhares de resistência e desconfiança com relação às promessas de que a mecanização, a industrialização e a transferência tecnológica chegariam ao "subcontinente" de mãos dadas ao progresso social. A partir de então, o documentário assumiu funções que vão além de sua concepção convencional como meio educativo dirigido a espectadores passivos, tornando-se ferramenta primordial para aproximar-se e descobrir o que está submerso, negado e desvalorizado na sociedade. Ele torna-se fonte de contrainformação que questiona as estruturas hegemônicas de comunicação, maneira de reconstruir eventos históricos e desafiar interpretações dominantes e frequentemente elitistas do passado. Ele tornase, ainda, modo de obter e preservar testemunhos de indivíduos ou grupos que de outra forma não teriam suas experiências registradas, instrumento para explorar as complexas relações de si com o outro e entre sociedades, possibilidade de consolidar identidades culturais e agendas ideológicas (BURTON, 1990). Os usos do documentário na América Latina, a partir de 1950, redefiniram a função social do cinema.

Após a Segunda Guerra Mundial, a sensibilidade individual e os interesses pessoais passaram a constituir o ponto de partida das propostas dos novos cineastas, que se desvinculavam das razões e apoio estatais e do studio system. Na América Latina, as novidades tecnológicas e de linguagem conjugaram-se à amplificação da mobilização social. A urgência da expressão pessoal foi quase invariavelmente circunscrita pela inescapável realidade conturbada, adquirindo dimensão política. Como comentou o cineasta uruguaio Mario Handler, "o cineasta inevitavelmente começa a tornar-se politizado, porque a situação existente o previne de ser apenas um cineasta"' (BURTON, 1990, p. 19, tradução nossa) ${ }^{2}$.

2 "The filmmaker inevitably begins to become politicized, because the existing situation prevents him from being simply 
Essa reformulação nos modelos e propósitos das realizações gera um impulso que move muitos cineastas a aventurar-se por remotos e negligenciados rincões de seus países para filmar o povo e as culturas que encontravam ali e, pela primeira vez, os marginalizados tinham um lugar à frente das câmeras. Através de documentários como Vuelve, Sebastiana (Jorge Ruiz, 1953, Bolívia), Mimbre (Sergio Bravo, 1957) e Trilla (Sergio Bravo, 1958, Chile), Araya (Margot Benacerraf, 1959, Venezuela), Aruanda (Linduarte Noronha, 1960, Brasil), Arraial do Cabo (Mário Carneiro e Paulo César Saraceni, 1960), e dos inúmeros curtas que o peruano Manuel Chambi realizou a partir de 1956, antecipavamse as ideias sob as quais Fernando Birri reuniria os cineastas latino-americanos por meio de seu "filme-manifesto" Tire dié (1960, Argentina) e do texto Cine y subdesarrollo (1962). Os países subdesenvolvidos necessitavam um cinema que os desenvolvesse, esclarecesse, inquietasse e despertasse uma consciência revolucionária, e que tivesse a realidade como matéria-prima, problematizando-a para incitar a reflexão.

No contexto de todos esses trabalhos da formativa década de 1950, Araya ocupa um lugar ambíguo. Exibido em 1959 no Festival de Cannes, onde dividiu o Prêmio Internacional da Crítica (Fipresci) com Hiroshima, mon amour, de Alain Resnais, e lançado comercialmente em diversos cantos do mundo, o filme não estreou em terras latino-americanas até 1977, quando entrou em cartaz na Venezuela. Atribuímos isso a um misto de desinteresse dos distribuidores locais e de uma doença que impediu a diretora de fazer uma versão em espanhol. Ao fazer um recorrido da recepção crítica de Araya, dentro e fora da Venezuela, Juliane Burton (2000) nota o lugar de destaque que o filme ocupou na história mundial do cinema e entre estudiosos estrangeiros, mas reconhece sua exclusão dos anais cinematográficos nacionais e latino-americanos, contestando seu papel fundacional. Entretanto, parece-nos equivocado ignorar Araya e as relações que estabelece com seus contemporâneos e conterrâneos nos inícios do Nuevo Cine Latinoamericano. Dessa maneira, buscamos resgatar o segundo e último filme de Margot Benacerraf, revendo seus laços estéticos e temáticos com os preceitos 
discutidos pelo documentarismo latino-americano a partir dos anos 1950, e analisando a forma como o filme se relaciona com o universo que representa.

A Venezuela viveu, no fim da década de 1950, a chegada da democracia representativa após duas grandes ditaduras que haviam preenchido a primeira metade do século XX. O general Juan Vicente Gómez esteve no poder de 1908 até sua morte, em 1935, proporcionando um breve período de liberdade plena até o golpe de 1948. Neste momento, uma junta militar ocupou o governo, o qual passaria às mãos de Marcos Pérez Jiménez em 1952. Na década de 1920, durante a ditadura gomecista, iniciou-se a exploração das jazidas de petróleo na Venezuela, que ocuparia o primeiro lugar como exportadora do "ouro negro" até 1970. Na década de 30, o país petroleiro substituiu definitivamente o país agrário. Contudo, seria somente sob o governo personalista e autoritário de Pérez Jiménez que a Venezuela ganharia um verdadeiro impulso financiado pela exploração do petróleo através de monumentais obras de infraestrutura, de rodovias a conformação de centros urbanos, de universidades a monumentos. 0 país pujante e em franco desenvolvimento, aberto à imigração e com um projeto promissor, preparado para o estabelecimento da democracia, era o oposto do que vemos em Araya, que ignora esse vertiginoso apogeu.

Até então, no geral, os filmes venezuelanos se apoiavam em temas folclóricos, na celebração do imaginário nacional através do exótico ${ }^{3}$, como os ritos afro-venezuelanos, no comediante do momento no rádio, ou em histórias melodramáticas inspiradas nas películas argentinas e mexicanas, que dominavam o mercado hispanoparlante na época. Apesar da tentativa de estabelecimento de uma indústria cinematográfica a partir de $1940^{4}$, com a criação da Condor Filmes, as produções eram esporádicas, sem esboçar continuidade. A Condor da América Latina, como com a ranchera mexicana, o tango argentino, ou o carnaval nas chanchadas brasileiras. 
Filmes desapareceu para dar lugar, dois anos depois, à Bolívar Films, que foi crescendo ao se associar com os pequenos produtores do país até chamar a atenção do Estado, que passou a financiá-la a partir de 1945.

Como comenta Margot Benacerraf em entrevista a Fernando Pérez, "fazer um filme era como começar a história do cinema de novo" (1973, p. 86, tradução nossa $)^{5}$. Margot Benacerraf estudou drama em Nova Iorque e ingressou no Institut des Hautes Études Cinématographiques (IDHEC), em Paris. Durante uma viagem a Caracas para visitar o pai doente, em 1951, foi convidada a fazer um filme sobre o artista plástico Armando Reverón. Na época o pintor era ainda desconhecido, mas se tornaria um ícone da nação era identificado apenas como "o louco de Macuto". Reverón $\left(1952,23^{\prime}\right)$ teve que ser levado à Europa para revelação, já que não havia laboratórios na Venezuela, e fez sua estreia também no velho continente ${ }^{6}$.

Após Reverón e alguns projetos inconclusos, Margot Benacerraf começou a trabalhar em um tríptico no qual buscava fazer um panorama da realidade venezuelana. Batizado de Tres historias ${ }^{7}$, era formado por um relato sobre as planícies, baseado em um conto de José Rafael Pocaterra); as montanhas, elaborado por Benacerraf após uma temporada nos Andes Venezuelanos; e o mar. Com os roteiros das duas primeiras partes finalizados, a cineasta viajou à península de Araya para pesquisar sobre o mar, depois de ver uma foto do local no jornal, durante uma visita à casa de amigos. Margot Benacerraf viveu um tempo em Araya e decidiu descartar as demais histórias.

\section{Araya: odisseia do cotidiano}

Benacerraf acercava-se à Araya da mesma maneira que se aproximava de Reverón: com panorâmicas e travellings que vão formando círculos concêntricos,

No original: "Hacer una película era como empezar de nuevo la historia del cine". 
de fora para dentro. Em Reverón, ela passeia pelo lado de fora da fortaleza que o pintor havia construído para ele, chamada Castillete. Então traspassa suas muralhas e faz um percurso circular em seu interior até penetrar em seu ateliê, onde o pintor, circundado de espelhos, ocupa-se de seu autorretrato. Na cena das bonecas, a câmera segue rodeando, até adentrar completamente no espaço físico e espiritual de Reverón ao simular a atmosfera alucinatória na qual o artista vivia mergulhado devido a seus constantes ataques de loucura. A circularidade é elemento de destaque em Araya. Estrutura-se um ciclo de 24 horas, também como em Reverón, nas quais os habitantes da península refazem, em cerimoniosa coreografia, a ronda natural que aquela paisagem predestinou para suas vidas. Trata-se de um dia comum que acontece há 450 anos e se repete indefinidamente.

No breve prólogo, a câmera enquadra, de perto, pedaços do céu, do mar e do deserto. A música misteriosa gera tensão e expectativa, frustradas pela locução, tão árida quanto a paisagem: "Naquela terra nada crescia, e tudo era desolação, vento e sol". E completa: "Das bodas do mar e do sol, nascia o sal". Um fade out antecipa o turning point que aquele cenário atemporal irá viver. Sua história vai começar, estamos em 1500, e a câmera varre Araya como se registrasse o olhar dos primeiros espanhóis que aportaram nessa terra onde "nada crescia, e tudo era desolação, vento e sol". Entretanto, haverá vida a partir de agora. O sal, tão apreciado quanto o ouro, encherá Araya de homens, que encherão milhares de navios com direção à Europa.

Recorta-se a fortaleza, a segunda mais importante das Índias Ocidentais, em contra-plongée, e apenas o céu enquadra seus muros e seu canhão, tamanha sua grandeza. A música épica reinicia-se e, junto às palavras do locutor, encerra um caráter aventureiro àquelas imagens ermas nas quais, o que vemos, em contraste, é só desolação. O prólogo termina com uma exposição sobre o fim da belle époque de Araya. Ao invés de planos estáticos, a câmera move-se furiosa ao filmar a fortaleza, como simulando sua destruição e transformação em ruínas. 450 anos se passaram, mas dessa vez não há fade, nem música, para indicar que algo mudou/irá mudar. Ao contrário, mais um amanhecer, como tantos outros, vai começar. 
A câmera por detrás de uma enorme pirâmide de sal para rodear a inevitável repetição que é a vida naquela península. Margot Benacerraf acompanha três famílias que se enredam na conformação da economia precária de Araya. Temos os Pereda, cujos homens, Beltrán, o pai; Fortunato, César e Toñico, os filhos, são salineiros da noite, enquanto a irmã de Beltrán, Luisa, fabrica potes de barro, e sua esposa, Daria, cuida dos afazeres domésticos. Temos os Ortiz, que vivem da pesca, Adolfo trabalha no mar, sua esposa Isabel alimenta os povoados da península vendendo peixe, as filhas Angélica e Carmen, junto à avó, se ocupam da casa. E temos os Salazar, Dámaso, Nemesio e Benito são salineiros do dia, Petra, a mãe, é empacotadora de sal ao pé das pirâmides, e a filha, Nelita.

A câmera flutua em volta da salina e dos trabalhadores e de todos os ângulos enfatiza o que a locução afirma ser "os mesmos antigos gestos, sob o mesmo sol, hoje como ontem, durante séculos". As pirâmides materializam o trabalho faraônico realizado, e os homens andando em filas entre elas estrutura um padrão de movimento que confirma a submissão a uma ordem que nunca é nomeada, desfazendo-se assim em uma característica divina ou natural - portanto, invisível.

Segundo o locutor, o tempo não se detém jamais. Todavia, parece que os homens de Araya estão fadados a ficar parados nele e na circularidade de seus gestos. A ronda não pode e não deve ser interrompida, e os meneios são perpetuamente retransmitidos de pai a filho. Mais tarde, entendemos o conceito de tempo usado pelo locutor. Ali, ele é um relógio de areia indefinidamente virado. "Ir e vir", "até o fim dos tempos", "outra vez", "uma noite mais", "toda manhã", "também", "de novo", expressões insistentes na voz sóbria que emoldura a cadência dos salineiros e dos pescadores. O barco que transporta o sal para longe da península é a única relação com o mundo de fora. Araya é um mundo fechado, a-histórico, em constante movimento, mas estático, pois gira em falso. É um universo sem possibilidade de escape, um lugar fabular onde o tempo é moldado por ritmos manuais e corporais implacáveis.

A mise en scène é elaborada em função da potencialidade do espaço, que não é neutro, pois carrega consigo muitas significações que contribuem 
para o desenvolvimento do relato. O espaço adota papel ativo e uma influência determinante sobre aqueles que o ocupam, sendo um elemento de função dramática preponderante. O sal onipresente machuca, consome os pés e faz feridas profundas. O sol açoita com vigor, o pó está cada vez mais queimado, e nessas terras nada cresce. Toda a vida provém do mar, e o resto é desolação. Quando o sol se retira, o vento se apossa da península, sem dar trégua a seus habitantes. Ao se dedicar ao embate entre o homem e a natureza, Benacerraf se aproxima de Flaherty, que extrai do próprio ambiente os elementos fundamentais do drama. Ainda, não se limita a mostrar, mas planeja uma encenação que acentua a situação que se quer colocar em evidência. A câmera se concentra no trabalho ritual para criar uma série de impressões visuais, propondo uma relação contemplativa ante a realidade filmada. Margot Benacerraf sincroniza movimentos, ordena objetos, cala seus personagens, e ajusta paisagem física e humana em uma ordem rítmica.

Exatamente na metade do filme, quando é meio-dia em Araya, a câmera se afasta lentamente dos povoados e das pirâmides de sal, voltando-se para o deserto, o mar, os cactos e os animais de feição pré-histórica que ocuparam a península milenar do prólogo. Araya passou, de 1500 a 1950, sem nenhuma evolução, e guarda não só o sistema de exploração primitiva do sal, mas também um mundo antigo que havia sido conservado intacto. Quando chega a noite, e os salineiros voltam a encontrar seus gestos da véspera, uma explosão rompe a languidez imemorial de Araya. A música heroica que acompanhava a chegada dos espanhóis, em 1500, é retomada e escolta caminhões, esteiras, máquinas, tratores. Essas imagens possuem textura de arquivo, como se constituíssem uma velha novidade.

E o são: a montagem paralela da atividade das máquinas triturando pedras e da hélice que arrasta dezenas de barcos, alternando-se com o esforço dos braços que cortam galhos secos, moem o milho, sovam o sal, carregam as $\operatorname{maras}^{8}$, só reforça o ciclo de exploração ao qual Araya está condenado. O epílogo 
é igual ao prólogo e seus planos de mar, céu, deserto, sal, desolação, vento, sol e música imponente. Do passado ao presente, o passado é o presente.

A introdução de maquinário na península evoca o clímax do descobrimento. Ambos são regimes de extração impostos pelo exterior, e marcam momentos históricos identificados como intrusões violentas. A conquista colonial se iguala à modernização industrial neocolonial (BURTON, 1990). O descobrimento da América havia sido um genocídio e não havia motivos para celebração. Essa correspondência revela o receio do filme com a "ruptura" que o desenvolvimentismo oferece. Araya não pretende defender um status quo ou embelezá-lo, rechaçando a possibilidade de mudança, e sim questiona a validade do rompimento maquiado, que apenas reproduz formas de violência: histórica, econômica, política e cultural.

Em entrevista a Pérez (1973), Margot Benacerraf afirma que se interessava em transpor para Araya, um pouco alegoricamente, por meio de um ponto de vista humano, um problema da Venezuela. "Uma mudança que durou de um a dois meses logrou transformar Araya na planta de sal mais moderna da América Latina, mas as estruturas seguiam sendo aquelas de um mundo velho, primitivo, rudimentar" (PÉREZ, 1973, p. 88, tradução nossa) ${ }^{9}$.

\section{As veias abertas da América Latina}

Araya tece inúmeras relações com outros filmes que se interessavam pela questão tradição/modernidade, na qual as sociedades do continente se debatiam. De um lado, há a urgência por registrar arcaicos modos de produção em extinção ao redor dos quais algumas culturas marginalizadas se organizavam. De outro, aparece a desconfiança e o questionamento das teorias desenvolvimentistas que invadiam a região.

Encontramos o destaque ao arcaísmo nas atividades de alguns grupos em El mégano (Julio García Espinosa e Tomás Gutiérrez Alea, 1955, Cuba), que trata

9 "Un cambio en un mes, en dos meses, logró transformar a Araya en la planta más moderna de sal de América Latina, pero las estructuras seguían siendo de un mundo anciano, primitivo, rudimentario". 
dos trabalhadores que retiram troncos velhos do fundo dos rios para a fabricação de carvão. Encontramos também em Aruanda, que aborda a formação de um quilombo e a vida rural da comunidade a partir de então, conduzida pelo ciclo econômico do algodão e da cerâmica. Ambos se instalam, de maneira marcante, em uma zona fronteiriça entre o documentário e a ficção. Os traços documentais se impõem nos planos dedicados ao trabalho e ao ambiente de vida das comunidades, que de imediato se confundem com uma encenação e narração que reconstrói tanto fatos históricos como situações cotidianas, inventando uma ficção.

Também podemos citar alguns filmes da primeira fase da Caravana Farkas ${ }^{10}$ : Vitalino/Lampião (1969), Casa de farinha (1970), O engenho (1970) e Os imaginários (1970), de Geraldo Sarno; A mão do homem (1969), A morte do boi (1970) e O homem de couro (1970), de Paulo Gil Soares. Em todos eles, após uma pequena introdução de caráter histórico, acompanhamos o ciclo completo de desenvolvimento de um produto desde a elaboração da matéria-prima, passando por sua transformação artesanal, até a chegada aos mercados. Ecoa a frase "os métodos são primitivos", deixando claro que as ferramentas usadas são funcionais, mas nunca tecnicamente adequadas. A admiração pelo virtuosismo dos trabalhadores esmorece ante a situação trágica a qual eles estão submetidos, o que poderíamos resumir em um trecho da locução de Vitalino/Lampião: "no princípio, era o artesão (...), guardião da tradição e dos mitos pertencentes a todos. Fora do tempo, desconhecendo as mudanças que se passam em volta, o artesão é hoje um símbolo de pura ação prisioneira do passado".

Chircales (Marta Rodríguez e Jorge Silva, 1968-1972, Colômbia) parte do núcleo familiar para universalizar o tópico da exploração e é mais marcado por uma consciência histórica, sendo a denúncia apenas o começo de um processo de pesquisa que busca entender como e por que a situação mostrada ocorre,

10 Caravana Farkas é o nome dado a um conjunto de documentários produzidos pelo fotógrafo Thomas Farkas entre 1964 e 1969. Primeiramente, o título se referia a vinte documentários sobre a cultura popular nordestina, reunidos sob o título A condição brasileira. Posteriormente, foram incluídos na Caravana outros quatro curtas-metragens produzidos por Farkas em 1964, os quais integraram o longa-metragem Brasil Verdade. Na mostra Caravana Farkas, realizada, em 1997, no Centro Cultural Banco do Brasil, somaram-se outros 14 títulos, produzidos pelo fotógrafo entre 1964 e 1980, totalizando assim 38 obras (RAMOS, 2007). 
e os motivos pelos quais é possível e perpetuável. Ao acompanhar a produção primitiva de tijolos nos latifúndios urbanos que rodeiam Bogotá, Chircales une as imagens chocantes do trabalho pesado, realizado inclusive por crianças muito pequenas, e aquelas do ambiente insalubre, com a narração que toca temas como a sistematização do abuso à qual os trabalhadores estão sujeitados. Tal sistematização é caracterizada pela existência de uma espécie de estrutura de castas rígida, que passa de geração a geração e pela impossibilidade de fuga ou mudança. Os únicos caminhos factíveis são a morte ou a partida a outro chircal. Ademais, destacam-se as diversas formas de alienação através da demagogia partidarista, da religião e do rádio, através do qual ouvimos a versão oficial do país, que contrasta com a imagem bruta da realidade.

Arraial do Cabo, El hombre de la sal (Gabriela Samper, 1969, Colômbia) e Viva Cariri! (Geraldo Sarno, 1970, Brasil) dedicam-se à confrontação, "em nome do progresso", entre o arcaico e o moderno. A enérgica chegada da industrialização em lugares marginalizados é colocada de maneira tensiva ao espectador.

Arraial do Cabo retrata o cotidiano de uma comunidade de pescadores inteiramente dissolvida pela instalação de uma indústria nas redondezas. Opta por um olhar harmonioso sobre o ciclo econômico retratado e pelo registro poético desse modo de vida prestes a desaparecer que, assim como em Araya, colide com a maneira épica das máquinas realizarem o trabalho. Essa mudança de registro faz sentir a agressividade com que essas alterações são impostas. Já as estratégias empregadas em El hombre de la sal, aproximam-no de El mégano e Aruanda. Constrói-se um conto que, no filme de Gabriela Samper, é guiado através de uma canção, silenciada pelos ruídos de imponentes chaminés, cujo aparecimento esvazia as galerias subterrâneas onde o velho salineiro Don Marcos Olaya trabalhava.

Em Viva Cariri! há uma cena em que a imagem é rebobinada e os romeiros aparecem andando para trás. Ela se liga estreitamente à circularidade que caracteriza o filme de Benacerraf, a qual expõe o estancamento de Araya. Viva Cariri! aponta a decadência econômica do Vale do Cariri e traça uma 
relação entre a economia local e a religião, buscando demonstrar que a religião acentua a alienação política da população e, em decorrência disso, incentiva a aceitação passiva da radical desigualdade socioeconômica da região (RAMOS, 2007). Em sua montagem fragmentária, que sugere relações estreitas entre fé e alienação/política e religião, convivem e confrontam-se diversas abordagens. Essa construção através de uma multiplicidade de vozes conecta o filme de Sarno de maneira peculiar à Araya.

Quando falamos de $v o z$, nos referimos ao conceito de voz do texto desenvolvido por Bill Nichols (2005). A voz é mais do que a narração ou o diálogo, é algo formado pela interação de todos os códigos de um filme. É a maneira como ele organiza aquilo que apresenta. Com exceção de Araya e Viva Cariri!, poderíamos caracterizar todos os documentários elencados nesta seção como expositivos. Para Nichols, o modo expositivo é um dos seis modos de representação nos quais o gênero documentário se divide: poético, expositivo, participativo, observacional, reflexivo e performático (NICHOLS, 2008). O modo expositivo está ligado a uma postura argumentativa, na maior parte das vezes apoiada num comentário com voz de autoridade, através do qual o filme se dirige diretamente ao espectador. No filme expositivo, todos os elementos se articulam de forma subordinada a esta voz de autoridade, que expõe um argumento. Em geral, a imagem tem um papel secundário, de ilustração ou esclarecimento do que é dito.

A voz de autoridade, como identificada por Nichols, guarda semelhanças com a voz do dono, do modelo sociológico proposto por Jean Claude Bernardet (1985). Esse modelo poderia ser entendido como um modo de fazer documentário, onde a estrutura do filme se organiza a partir de uma voz off autorizada e arrogante, a voz do dono, também denominada voz de Deus, que apresenta uma tese. Resumidamente, a comprovação desta tese se dá a partir da articulação entre o locutor principal, que representa a voz do saber, e os entrevistados, que falam apenas sobre suas próprias experiências, sem nunca propor generalizações.

Viva Cariri! rompe com o esquema rígido dos outros filmes da Caravana Farkas citados. Propõe interrelações entre os assuntos abordados, e não uma 
tese linear. O modo como o filme dialoga com seus objetos e personagens é mais horizontal. A voz autoritária e onisciente, que não desaparece, compartilha espaço com uma diversidade de procedimentos, como as entrevistas que não se subordinam a comprovar a locução, a revalorização da experiência subjetiva, e a busca pela problematização no lugar da apresentação de uma conclusão fechada.

Araya opera de maneira diferente essa ruptura. As imagens se desdobram a partir da trilha sonora, entrando em constante conflito com a música e a voz over. Isso gera estranhamento e ressignifica o relato, um pouco à maneira de Terra sem pão (Las Hurdes, Luis Buñuel, 1933). O documento imediatamente visível, ao adentrar o processo de narração, nasce de novo. Algo arde constantemente no fundo de Araya, e Margot Benacerraf busca fisgar o oculto em meio ao evidente, e as turbulências embaçadas pela narrativa clássica.

Assim, as imagens documentais se contrapõem a uma poetizada trilha sonora, rigorosamente manipulada. Os cantos milenares que acompanham o trabalho do sal invadem os solitários desertos de Araya, enquanto os povoados descansam em um estranho silêncio, acusando o torpor reinante. A sobreposição das ladainhas das mulheres vendendo peixe transforma-as em um mantra hipnótico e perturbador. As várias capas de ruído das ondas na visita ao cemitério o situam em um ambiente submarino ${ }^{11}$.

Por outro lado, a locução, uma voz masculina pertencente a outro universo que nunca se especifica, é monocórdica, grave e objetiva, e está sempre em primeiro plano sonoro. Há duas atitudes do locutor que chamam a atenção. Ele desfia dados absurdos com naturalidade: os vinte quilômetros que os Pereda devem caminhar diariamente para ir e voltar das salinas, a lavagem do sal como única lembrança de infância do pequeno Toñico, a privação inevitável em que sobrevive Carmen, a violência com que o capataz rejeita a mara com peso incorreto de Benito. Ou então ignora despreocupadamente imagens perturbadoras: os pés descalços no sal abrasador, as crianças sujas e nuas, as casas precárias, a

11 Margot Benacerraf conta sobre o processo de sonorização da sequência do cemitério marinho em entrevista a César Cortez no programa Obra \& Arte (2001). 
magra refeição, os animais mortos, os urubus que competem com os homens pelos peixes. Esse distanciamento acusa a principal violência que Araya procura abordar, subvertendo a voz de Deus, que fica desautorizada.

\section{Palavras finais}

O desejo de revelar as realidades conflitivas de seus países estimulou os cineastas latino-americanos a explorarem o potencial político do meio a partir de 1950. Correspondendo ao clima social e político que envolvia o continente, os diretores procuraram maneiras de usar os filmes como instrumentos de reflexão e discussão. 0 longa de Margot Benacerraf, Araya, ocupa um lugar incerto na história do cinema da América Latina. Por vezes, devido a suas virtudes plásticas e sua sensibilidade social, é considerado uma obra de transição entre o classicismo da tradição documental e a renovação que se encontrava em plena gestação. Em outras, é considerado um exilado, que não poderia ser tomado como precursor dos nuevos cines que rebentariam na década de 60, já que sua primeira projeção na região realizou-se somente em 1977.

Frente à inexistência de material em português sobre o filme e sua diretora, buscamos apresentar as preocupações de Araya, que se conectavam com o contexto cinematográfico latino-americano. Além disso, procuramos estabelecer um diálogo com outros documentários que, como o filme de Benacerraf, dedicavamse ao registro de formas de trabalho locais vistas como ameaçadas pelo processo de modernização em curso e, ao lado da dimensão antropológica de registro, desenvolviam uma dimensão crítica dos processos exploratórios arraigados no continente: a contínua experiência histórica de mutilação e desintegração disfarçadas de desenvolvimento, a qual o escritor Eduardo Galeano esquadrinhou em As veias abertas da América Latina, lançado em 1971.

"Era, haviam dito, um país de uma riqueza fabulosa. Um país onde nada muda", conta o locutor. O único vestígio de riqueza que advertimos em Araya encontra-se na frase "o sal valia tanto quanto o ouro", que ecoa, assim como tantas outras, enfatizando a estrutura narrativa circular do filme e o interminável ciclo ao qual a península está condenada. 


\section{Referências}

BERNARDET, J. C. Cineastas e imagens do povo. São Paulo: Brasiliense, 1985.

BIRRI, F. "Cine y subdesarrollo". In: BIRRI, F. et al. Hojas de cine: testimonios y documentos del Nuevo Cine Latinoamericano. Vol. I. Centro e Sudamérica. Cidade do México: Fundación Mexicana de Cineastas. Dirección General de Publicaciones y Medios. Secretaría de Educación Pública. Universidad Autónoma Metropolitana, 1988.

BURTON, J. "Araya across time and space: competing canons of national (Venezuelan) and international film histories". In: NORIEGA, C. (ed.). Visible Nations: Latin American cinema and video. Minneapolis: University of Minnesota Press, 2000. . (ed.). The social documentary in Latin America. Pittsburgh: University of Pittsburgh Press, 1990.

GALEANO, E. Las venas abiertas de América Latina. Buenos Aires: Catálogos, 2007.

GRIONI, L. Margot Benacerraf. Caracas: Fundación Cinemateca Nacional, 2009.

NICHOLS, B. "A voz do documentário". In: RAMOS, F. (ed.). Teoria contemporânea do cinema. Vol. II. Documentário e narratividade ficcional. São Paulo: Senac, 2005. . Introdução ao documentário. Campinas: Papirus, 2008.

PÉREZ, F. "Cuatro entrevistas en Venezuela: Margot Benacerraf, Jesús Enrique Guédez, Mauricio Wallerstein, Grupo de Cine de la Universidad de Los Andes". Revista Cine Cubano, Havana, número 89-90, 1973. 
RAMOS, C. As múltiplas vozes da Caravana Farkas e a crise do modelo sociológico. Dissertação (mestrado). Universidade de São Paulo, São Paulo, 2007. Disponível em: http://www.cenacine.com.br/wp-content/uploads/clara-leonel-ramos.pdf. Acessado em: 20 nov. 2012.

submetido em: 16 ago. 2013 | aprovado em: 03 set. 2013 